\title{
Conservation philosophy in action: examples of structural intervention in the United Kingdom and the export of national practices
}

\author{
J. D. Miller \\ Historic Structures, Gifford - Part of Ramboll, UK
}

\begin{abstract}
This paper states principles of structural conservation as held in the UK, examines them in the context of project examples within the country and looks at recent cases where the same ideas have been applied to projects overseas. It concludes by asking how our own national techniques should be translated to other countries.

The origin of conservation philosophy and principles in the UK is examined, beginning with the nineteenth century activist William Morris. The basic principles considered include an options appraisal, the principle of reversibility and need to keep faith with use of original materials and load paths. The application of principles is briefly examined through projects that include conservation in the Palace of Westminster, ironwork repairs at Tynemouth Station in Newcastle, new facilities at Wells Cathedral and the restoration of the landscape around Chiswick House in London. The export of these principles is examined through projects on stone buildings in Abu Dhabi and Trinidad. The paper concludes that the UK approach may vary slightly from others because of a background of low seismic activity and simple interventions, but that international practice remains a balanced skill, marketable across frontiers.

Keywords: William Morris, conservation principles, reversibility, options appraisal, minimum intervention, national practice, seismic retrofitting.
\end{abstract}




\section{Introduction}

The origin of the modern conservation movement in the United Kingdom is found in key individuals of the nineteenth century. The leading characters in enacting change were on the one part William Morris, who along with other close friends created the Society for the Preservation of Ancient Buildings (SPAB) in 1877, a forerunner of many modern pressure groups and amenity societies, campaigning tirelessly to preserve endangered buildings and obtain an Act of Parliament that would enshrine protection, and on the other part Miss Octavia Hill, Sir Robert Hunter and Canon Hardwicke Rawnsley who created the National Trust in 1895. Thus within twenty years two organisations were formed that became fundamental to the conservation movement in the UK: one a body of philosophy and public rhetoric and the other a body of purchase and restoration. Today the National Trust and English Heritage together have around 4 million paid-up members, an extraordinary figure, showing just how much a popular appreciation of heritage exists in the national psyche.

William Morris held strong personal views on the nature of conservation. He was fuelled by a friendship with the admired philosopher John Ruskin. Ruskin used the familiar Western European idea that the value of an historic building lies in its sheer age and continuity of presence, supplementing this not with minutia of detail but with broad concepts such as 'Memory' and 'Power'. Morris went beyond this, writing to capture the mood and feel of buildings. He used sentiments familiar to the public in argument and discussion to support his views. These continue to live deep in the minds of heritage professionals working in the UK today. In words drilled into to the UK practitioner, he described our duty as being 'to stave off decay by daily care, to prop a perilous wall or mend a leaky roof', by which he meant that an essential element of practical conservation was a basic regime of maintenance. However, whilst much of his ideals remain vibrant and fresh, he also made bold statements that put the function of the building as being utterly subservient to the fabric itself, saying that if a building 'has become inconvenient for its present use, to raise another rather than alter or enlarge the old... modern art can not meddle with (them) without destroying.' [1]. In this our modern processes might challenge him.

The need to protect UK heritage was given a second, strong impulse by a sense of public loss after the ravages of the Second World War. Huge numbers of buildings had been destroyed by bombing and many of Britain's historic country houses had been commandeered for use by the British Army and left to ruin. This led directly to the creation of a graded listing system in 1950. The significance of listing is the way in which value judgements of quality and rarity of valuable historic fabric would be assigned, with fabric being placed on the list and in different categories according to sets of value judgements; these being at the time in relation to uniqueness, architectural or technical merit, or sheer age. They were then essentially judgements in relation to the fabric itself, made in isolation and without social or cultural context, and made exclusively by specialist professionals. 
Since the mid-twentieth century conservation philosophy in the UK has been joined to an international development of conservation principles. The essentially European Charters of Athens (1931) and Venice (1964) achieved baseline values on which the growing international business of conservation could move forward, but Venice still had only 4 non-Europeans out of the 23 people on the drafting committee. Most would recognise that it was the Burra Charter (first published 1979) that brought New World thinking to bear and put words to the concept of sociological and cultural context of historic sites. Thus in the context of popular conservation - that is, how the non-professional might think - the cultural value of a historic building is still a relatively new idea.

Conservation philosophy in the UK has moved on significantly in the last twenty years. A better understanding of what brings risk upon historic fabric has led to a new approach to change. The arrival of the Conservation Management Plan has allowed context and use to inform and manage changes that might previously have been frowned upon. The result is a heritage industry that is geared to managing change as well as look after the status quo.

\section{Project-based application of conservation principles}

The vast majority of heritage project consultancy in the UK is undertaken by private consultancy practices. Local conservation officers and the government body English Heritage, acting in effect as regulators of historic intervention, work with reasonable transparency through the legislative systems and are active in setting down principles by which they will assess construction and maintenance work. The principles put forward by English Heritage in 2008 in their document Conservation Principles [2] included the following:

- It is essential to understand and sustain what is valuable in the historic environment

- $\quad$ Everyone can make a contribution

- $\quad$ Places should be managed to sustain their significance

- $\quad$ Understanding the value of places is vital

These principles require anyone making changes to a site to dig deep into the reasons why a site is important, but leaves the practitioners to justify decisions concerning elements of fabric.

As with professionals in any country, conservation practitioners in the UK are initially faced with many of their own value judgements when considering a project. However, with regard to disciplines, the UK engineer may often be more subservient to his architectural counterparts than, for example, in Italy, the Middle and Far East or South America in one key respect: seismic resistance. The engineer is guardian of the stability of the fabric. When seismic retrofitting is to be considered the engineer is responsible for potentially high levels of fabric intervention, and has a major role. In the UK, however, the infrequency and minor nature of seismic activity means that resistance is almost completely neglected from conservations and restorations. In this way UK conservation architects rightly expect the minimal level of structural work except for that 
strictly necessary to keep the building standing under gravity and wind load. As hurricanes are very rare, gravity will normally provide the only relevant loading.

The commonly-held personal philosophies of the UK conservation engineer are generally referenced through the national publications of English Heritage and not referenced directly back to the Athens, Venice or Burra Charters. These would include the following principles:

- $\quad$ Option appraisal: there is never a single structural solution. There will always be options for conservation work and a number of these should be examined. The prerogative of minimum intervention will mean that an option to 'do nothing' except monitor should always be considered, being rejected if this leaves the fabric at risk.

- $\quad$ Reversibility: any works should permit, where possible, removal at a future time so that original fabric can be identified and made distinct from the intervention.

- Keeping faith: the materials and structural systems used as an intervention should keep faith with the original construction. Load paths should where possible trace the originals, structural forms be maintained and the choice of materials kept in sympathy with the original in regard to both the fabric and engineering compatibility.

In addition, the following actions are generally taken by the professional during the execution of a commission:

- $\quad$ Gain an understanding of the existing sequence: conservation work cannot have meaning unless the historic sequence of construction is understood sufficiently well to define one age from another.

- Learn from building types: historic buildings rarely exist as individual examples, and the engineer should seek the experience of others in research and discussion to build up a picture of the likely behaviour of the buildings we encounter.

- Archive: professionals have an obligation to record of things uncovered, and a greater obligation to record things removed. Archaeological and Building Recording disciplines run in harness with the work of the Conservation Engineer.

\section{Application of conservation principles in the United Kingdom}

Basic conservation engineering principles are applied as the project develops, usually with brief dialogue through statutory processes. The following projects show examples of the principles of conservation engineering in action in the UK context:

\subsection{Household Cavalry Museum, the Horse Guards, London}

To the tourist, the magnificent Horseguards building dating from 1755 looks immaculate, but in fact parts have settled by $200 \mathrm{~mm}$ and the walls bulge out by 
up to $150 \mathrm{~mm}$. Therefore plans to restore the internal space by removing an intrusive 1920's concrete mezzanine floor from within the vaulted ground floor were rightly regarded with alarm by the engineers, as the inserted floor was almost certainly providing lateral restraint to the vaulting at the spring point of the arches. The easiest solution might have been to restrain the tops of the columns with visible steel ties, but in practice there was just sufficient depth within the vaulted floor to direct the lateral ties down at an angle from the first interior column line, thus providing a stable system of wall restraint (figures 1 and 2). This solution kept faith with the original design and was the least visually intrusive. However, the tied column solution would almost certainly have been adopted in a seismic environment.

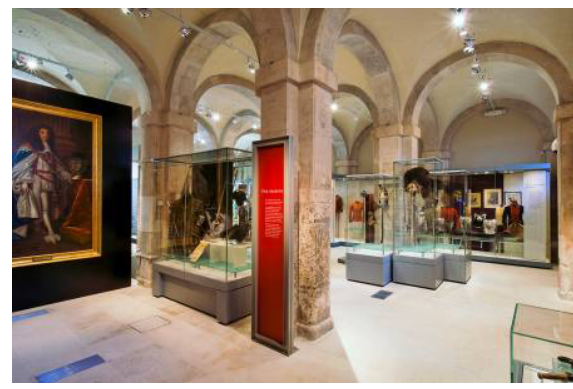

Figure 1:
Existing masonry vaults in Household Cavalry Museum.

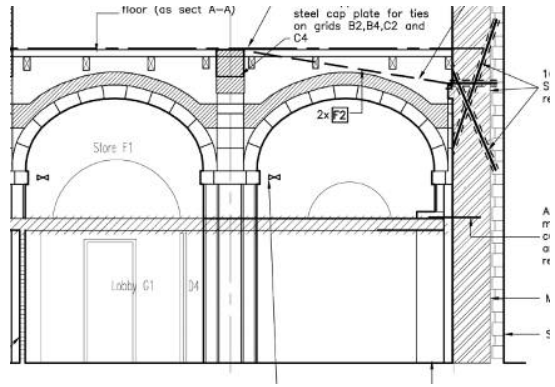

Figure 2: Lateral tying of external walls.

\subsection{Westminster Hall, the Houses of Parliament, London}

The Houses of Parliament are part of the Place of Westminster, a UNESCO world heritage site, and Westminster Hall dates from 1095, at which time it was the largest medieval hall in Europe. The south end of the Hall was remodelled around 1840, with heavy elements of stone and lime concrete being introduced, and this addition of load resulted in settlement that had been progressive in the last 40 years and probably for much longer. The steps had settled by up to $180 \mathrm{~mm}$ and the lips on the corners of stone slabs had become a serious trip hazard to the elderly.

The lead consultancy role on the project was given to the engineer as the defects were clearly caused by ground movement. The possibility of substantial and significant archaeological subsoil record was high and the historic value of the site very high indeed. This dictated a comprehensive and conclusive phase of investigation and a rigorous options appraisal, so that an accurate diagnosis and well-argued solutions could be offered. A layer of very weak alluvial clay from the River Thames was found under this part of the hall floor, at depths of between $1 \mathrm{~m}$ and $3 \mathrm{~m}$ below the floor. The solution adopted was that of compaction grouting, a controlled form of insitu ground compaction using a highly viscous grout. This was chosen to preserve the basic stratigraphy of the 
ground whilst providing local support to the stone floor. More intrusive systems such as piling or low-viscosity grouting were unacceptable on the grounds of intervention. Even so, a large part of the floor and steps at the south end of the Hall had to be dismantled and later re-assembled to achieve the solution (figure 3). This was a project whose success was built on robust investigations, diagnosis and the range of options put forward, which enabled clear and transparent discussion with English Heritage [3].

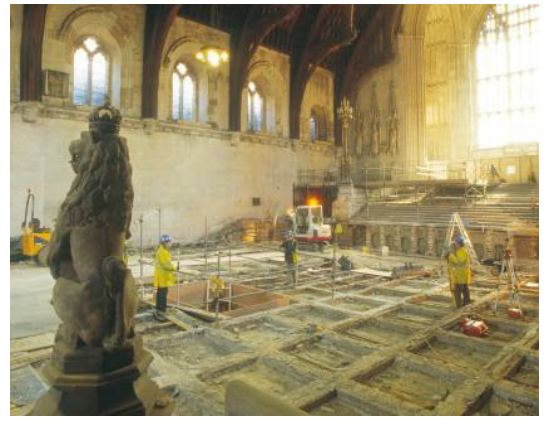

Figure 3:
Dismantled fabric in Figure 4: Westminster Hall.

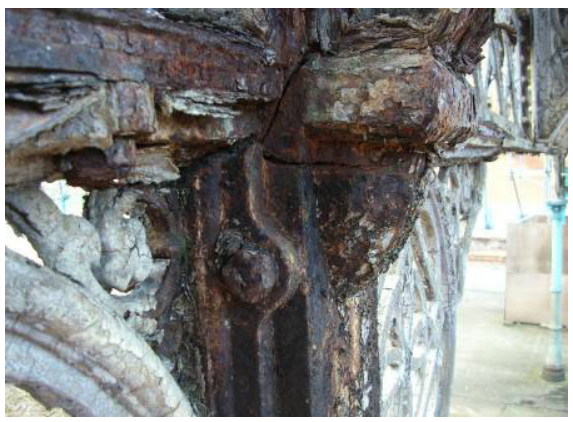

Cracking to cast iron columns at Tynemouth Station.

\subsection{Tynemouth Station Canopies, Newcastle upon Tyne, Northumberland}

Tynemouth Station in north-east England is a regional masterpiece in the use of cast and wrought iron, dating from the heroic age of Victorian railways. Built in 1882, its heyday ended with the First World War in 1914, after which it fell into decline as use of the station dwindled. In the mid 2000's it was placed on the English Heritage 'At Risk' register and appeared on the front cover of its At Risk Review in 2008. By then it was in an appalling state of decay, with corrosion throughout. With a proposal to develop it into a covered market and performance space, it is a clear example of the need to find alternative, economically sustainable uses for buildings and structures that no longer have a viable life performing their original function, if they are to survive.

A detailed structural survey revealed cracking through almost all the cast iron columns, at a level just above the impost, or seating, of the roof structure itself (figure 4). The cause of this is likely to have been jacking of the upper section by corrosion deposits on the impost, made worse by horizontal thermal racking movement along the $150 \mathrm{~m}$ canopy structure. However, by making a detailed consideration of all actions to which the canopy might be subjected, including accidental ones, the engineer was able to show that alternative load paths would exist provided that the supporting brackets and bolts were replaced to ensure that the connections were structurally sound (figure 5). In this way, the cracked columns would be maintained without repair, thus saving the historic fabric from considerable trauma by the unnecessary replacement of columns. This was a 
challenge to the client and contractor, who might have expected to see the full repair of all damaged elements after investing in such a major restoration. It is fully justified on the grounds of minimum intervention.

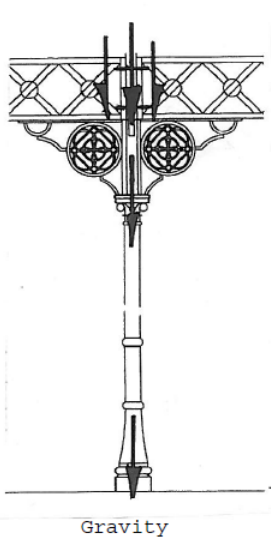

Figure 5:
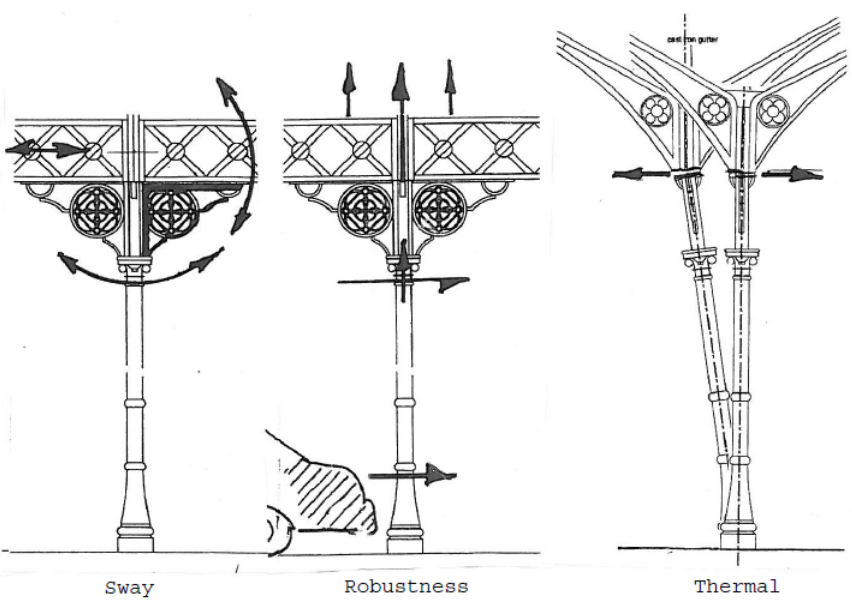

Structural actions on Tynemouth Station columns.

\subsection{New Interventions: Wells Cathedral and Chiswick House Café}

The principles of conservation where applied in the UK do not just apply to work that conserves fabric: they also apply to work that touches and respects the historic fabric, even if it is new. Indeed, in reality much of the conservation engineer's time is spent in designing new structures in the context of old.

The new facilities recently completed at Wells Cathedral in Somerset show the respect of the new works to the old fabric in both foundations and masonry superstructure. At Wells, one new building has been constructed with a $300 \mathrm{~mm}$ thick concrete raft foundation that sits over the archaeological record of a fourteenth century medieval school. Another building foundation cantilevers out over a medieval water culvert, avoiding placing load on it. Load paths are kept distinct wherever possible, so that the fabric interventions are clearly legible and reversibility is maximized. A major intervention in terms of philosophy is the creation of the new opening in the side of the Thirteenth century wall to the Lady Chapel, behind the Choir, which allows access to new store and the undercroft to the Chapter House, previously closed to the public. This provides significantly greater functionality, and is highly significant in that it is the kind of intervention that William Morris would arguably have opposed (figure 6).

The new café at Chiswick is similarly respectful of the existing archaeology, a $250 \mathrm{~mm}$ thick concrete raft being founded less than $400 \mathrm{~mm}$ below the previous ground level in order to avoid disturbing the surviving foundations of a Tudor mansion that once used to occupy the site (figures 7 and 8). This minimal founding depth challenges UK practice, as it is shallower than the generally accepted frost zone, but was justified by local meteorological analysis. 


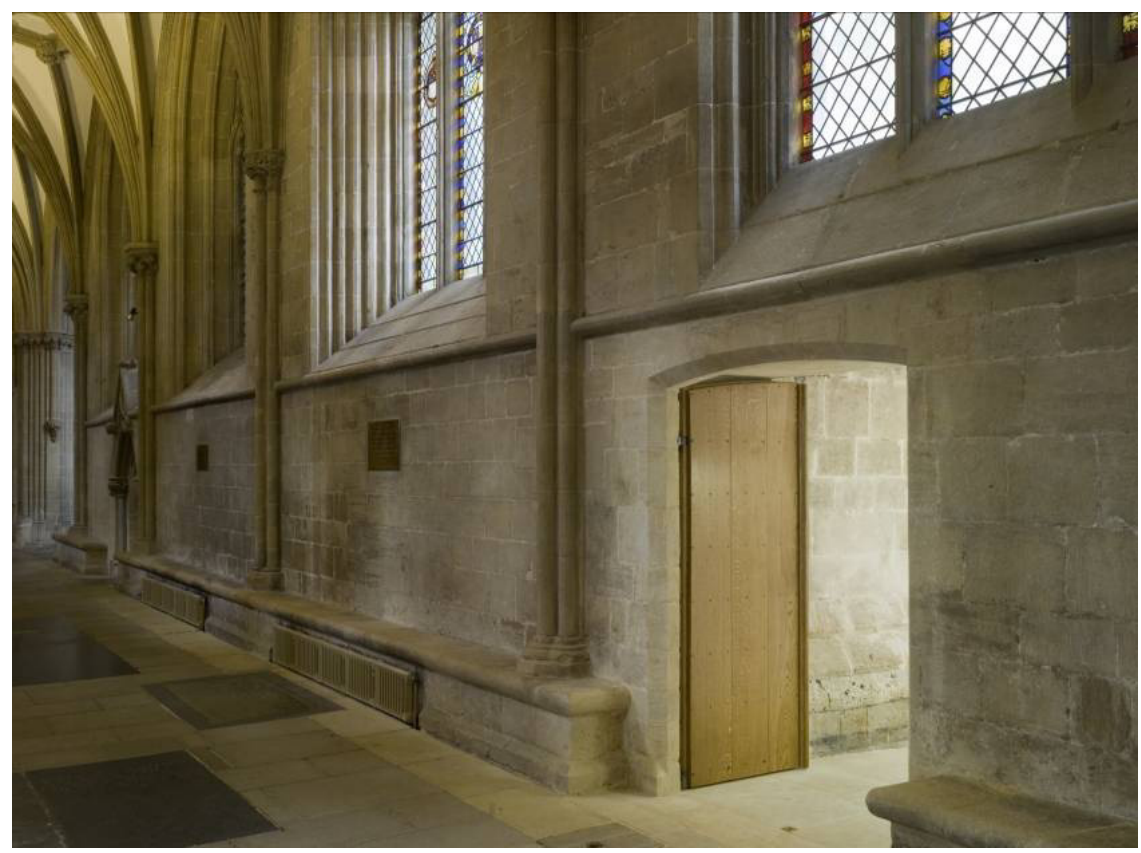

Figure 6: New opening in Thirteenth Century wall at Wells Cathedral.

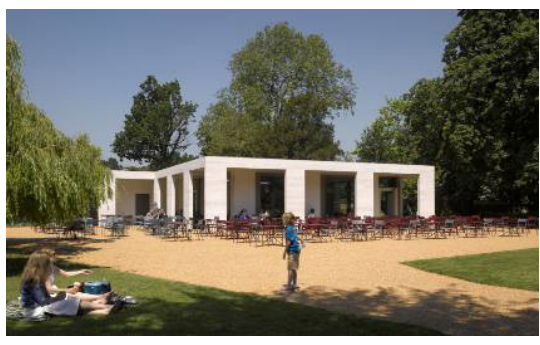

Figure 7: New café at Chiswick Gardens.

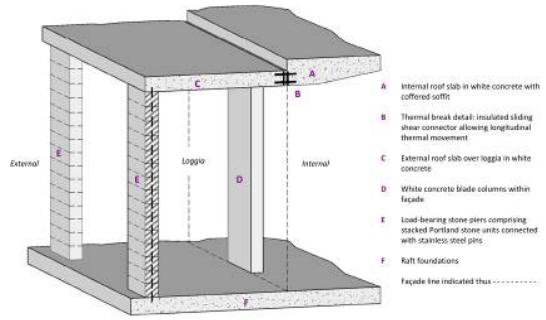

Figure 8: The café raft slab bears on archaeological remains.

\section{Conservation principles applied outside the United Kingdom}

The national reticence of the UK engineers to make bold interventions and the absence of seismic or intense meteorological activity mean that their structural solutions to historic fabric strengthening outside the UK can seem modest. Minimum intervention has, in particular, driven new ways of understanding the behaviour of masonry structures and new analyses to examine the effect of creating tensile capacity. 
For example, the Arctec ${ }^{\mathrm{TM}}$ solution of using drilled anchors, tested and in widespread use on highway structures in the UK, was in 2004 extended for use in the US on Wisconsin Bridge, built in 1833 and the oldest masonry arch structure in Washington DC (figures 9 and 10). More familiar solutions to this problem might have included the creation of a relieving arch or secondary beam structures above the existing masonry but in this case, by concentrating on an understanding the of performance of the existing fabric, the existing load path could be maintained and capacity enhanced.

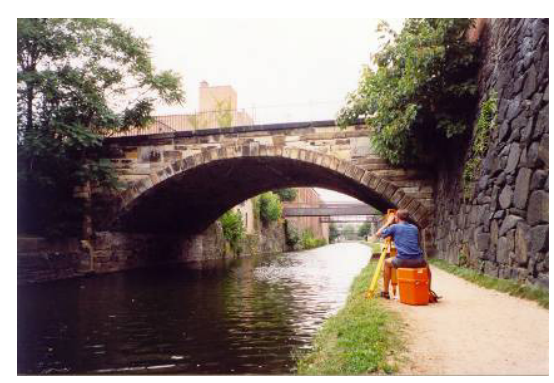

Figure 9: Wisconsin Bridge, Figure 10: Washington DC.

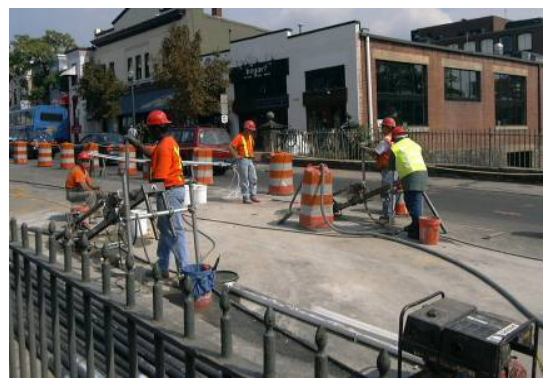

Drilled anchor installation at Wisconsin Bridge.

Recent work in Abu Dhabi has, amongst other ongoing restoration, examined the stability of a very fragile mudstone watchtower structure in Liwa Oasis, dating from the mid-nineteenth century. This small tower is an important record of architectural style and has been partly buried in windblown sand. Earlier nearby projects have sought to create robust reconstructions that the visitor can easily access and walk over. In this case the aim is to preserve as much of the existing fabric as possible, with stainless steel wires around the circumference, let into the random stone joints, a grouted core using local pozzolanic material and internal hoop restraint at level of the watchtower floor, now lost. The aim is provide the lightest possible touch to the delicate fabric. There is no consideration of seismic action in the conservation; there is very low risk to life should an event occur.

The basic component of Arctec - the grouted stainless steel Cintec Anchor TM has been widely used elsewhere. In the strengthening works on the Al Ghuri Mosque in Egypt in 1999, anchors were initially specified to provide simple stitching across substantial vertical cracks in the masonry (figure 11). However, there was concern over the interaction of stiff masonry box of the main enclosing walls and the minaret. Through development of non-linear discrete element analysis the simple conclusion was obtained that rigid stitching of minaret back into the walls would exacerbate damage during seismic activity (figure 12). The outcome was that the additional effort to understand behaviour had reduced the scope of the fabric intervention. Thus the power of modern computing techniques helped avoid over-zealous strengthening, which in previous generations have sometimes made up for lack of understanding of structural dynamics [4]. 


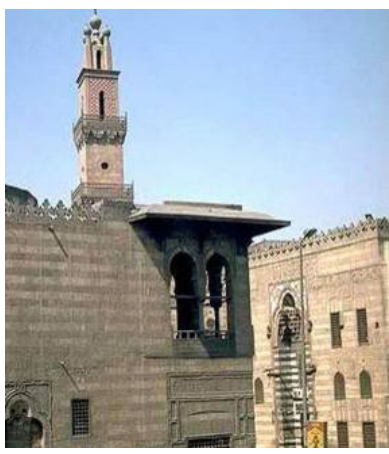

Figure 11: Al Ghuri Mosque.

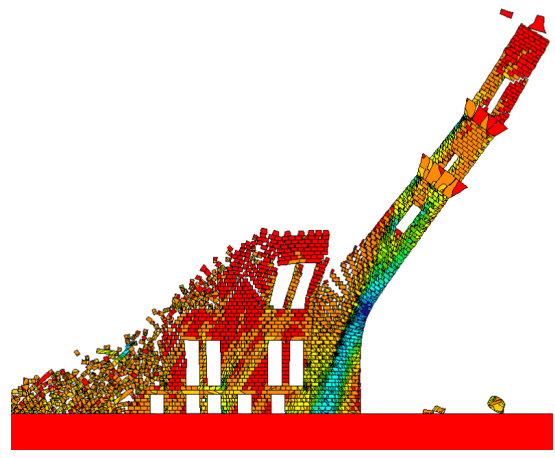

Figure 12: Discrete element analysis of Minaret.

The confidence placed in grouted anchor technology and the analytical methods related to such strengthening has enabled a number of more advanced retrofitting schemes to be recommended for various projects. The President's House in Port of Spain, Trinidad, is a colonial style building dating from 1874 which suffered partial collapse of a wing after a seismic tremor in 2010 (figures 13 and 14). The structural inspection of the standing fabric recommended various fabric repairs, such as timber truss ends, joist replacement due to termite infestation, repair of masonry cracks and installation of horizontal tying at eaves level. In addition, the possibility of seismic retrofitting was discussed, using anchor technology. The cellular nature of the building, the high quality of the blue limestone in the walls and the successful use of anchor technology for simple tying in nearby restoration works means that this is a viable option. Trinidad lies just west of the West Indies Arc tectonic zone: a 475 years return period earthquake is likely to have intensity VIII (Peak ground acceleration of approximately $0.5 \mathrm{~g}$ ) and 2475 years period an intensity X. A preliminary assessment concluded that retrofitting for life survival using a combination of drilled wall anchors for tensile masonry capacity and floor diaphragms for stiffness is certainly feasible for the 475 years return. At lower intensities the building would be expected to respond well with good fabric survival.

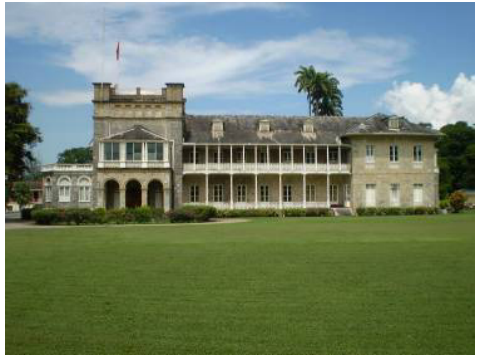

Figure 13: The President's House,

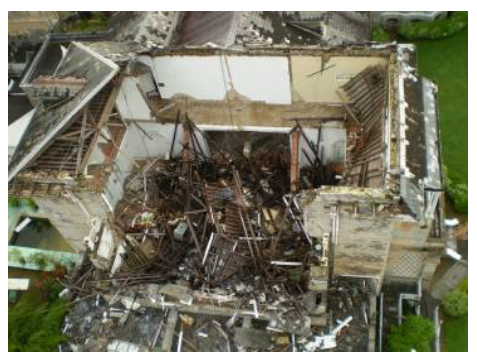

Figure 14: View of collapse of Western Wing. 


\section{Conclusion: the translation of our skills abroad}

The Victorian pioneer William Morris was fond of controversy, if it meant that principles of conservation were given public attention. However, in 1879 he famously made himself very unpopular with the Venetian authorities with his campaign against work being undertaken to the facades of San Marco, raising a petition that was signed by senior figures in the British establishment and sent to Italy. The application of conservation principles outside our national boundaries sometimes requires a delicacy and diplomacy that this episode failed to demonstrate.

Thankfully, a European stage for shared conservation practice has existed since Athens in 1931, and a world stage arguably since Venice in 1964. The role of International Charter is to ensure consistency, and the regular conferencing of which STREMAH forms a vital part - ensures that international experience is aired and levelled by the exchange of ideas. However, variations will inevitably persist, driven by national experience and individual zeal.

The philosophies employed and techniques developed by conservation engineers working in the UK are unlikely to be significantly different to those working in other signatories to the International Charters. However, the conservation professional in the UK is schooled in working in an environment of minimum intervention and low seismicity, and this drives the solutions they develop both at home and abroad. This can lead to solutions that the client may not have expected.

When selling this expertise abroad to countries where the non-professional has grown up without familiar ideas of heritage protection, this can result in practical solutions that challenge the status quo or established wisdom. Clients may find that they are offered lower levels of intervention than anticipated and local advice may be based on a much more interventionist approach, more familiar to refurbishment than conservation.

A simple background of conservation philosophy certainly provides a basis on which we may market our skills across frontiers. It challenges us to help inform others, as we ourselves have learnt. In this way we can achieve worldwide recognition of good conservation practice, experienced by example.

\section{References}

[1] Miele, E.C., Building Conservation and the Arts and Crafts Cult of Authenticity 1877-1939, Yale, 2005

[2] English Heritage, Conservation Principles: Policy and Guidance, 2008

[3] Miller, J.D., The Diagnosis and Arresting of Settlement within Westminster Hall in the Houses of Parliament, London; Proceedings of SAHC, Bath 2008

[4] Brookes, C.L. and Swift, R.J.R, Numerical Modelling of Masonry to Explore the Performance of Anchor Based Repair Systems and the Repair of Monuments in Cairo, Proceedings of ICOMOS Conference, Istanbul, 2000 